弾丸の変形に伴う弾径と腔旋痕角の变化（第 2 報)一パルティックの場合

\author{
水本光浩 \\ 熊本県警察本部刑事部科学捜査研究所 \\ 干862-8610 熊本市水前寺 6 丁目18番 1 号
}

\title{
Change of Diameter and Angle of Twist of Landmark for Bullet Deformation (2) - The Case of Paltik
}

\author{
Mitsuhiro Mizumoto \\ Forensic Science Laboratory, Kumamoto Prefectural Police H.Q. \\ 6-18-1 Suizenji, Kumamoto-shi, Kumamoto 862-8610, Japan
}

(Received 24 August 2009; accepted 14 December 2009)

Some .38 caliber revolvers smuggled into Japan are homemade guns called Paltik which were made in Cebu Island, the Philippines. Bullets fired from a Paltik have the following general characteristics;

(1) Rifling mark is rough and unclear because of the inferior processing of the finished rifling bore.

(2) Bullet is elongated because the bore diameter is usually smaller than an authentic gun.

But some Paltik bullets nowadays have a neat rifling mark. The diameter in the base of the lead bullet may have been changed thus having the rifling mark deformation become indistinct. In such cases, it becomes more difficult to distinguish fired bullets between those fired from a Paltik and an authentic gun.

In a former report, the maximun rate of contraction in the base of lead bullets and reduction of the angle of twist on the rifling mark fired from an authentic gun was indicated. But because the shape of bullets fired from a Paltik whose bore diameter is smaller, the deformation characteristic becomes long and narrow, so it is necessary to discriminate the characteristics of deformation on bullets fired from a Paltik and from an authentic gun.

In this study, .38 Special lead bullets were shot into thick steel plate in a right angle from a Paltik whose bore diameter is $8.45 \mathrm{~mm}$ (diameter of fired bullet is 8.58 $\mathrm{mm}$ ). The following results were obtained and it was concluded that there were few differences in characteristics of deformed bullets between a Paltik and an authentic gun.

A) The diameter in the base of bullets was contracted up to $0.59 \mathrm{~mm}(8.58 \mathrm{~mm} \rightarrow$ $7.99 \mathrm{~m}, 6.9 \%$ smaller $)$ in a Paltik. On the other hand, it was $0.60 \mathrm{~mm}(9.00 \mathrm{~mm} \rightarrow$ 
$8.40 \mathrm{~m}, 6.7 \%$ smaller) in an authentic gun.

B) The angle of twist of rifling mark reduced $0.75^{\circ}\left(6.90^{\circ} \rightarrow 6.15^{\circ}, 11 \%\right.$ smaller $)$ in a Paltik. On the other hand, it was $0.79^{\circ}\left(3.30^{\circ} \rightarrow 2.51^{\circ}, 24 \%\right.$ smaller $)$ in an authentic gun.

Key words: Paltik, Deformed bullet, Contraction of bullet diameter

緒 言

日本国内に密輸される口径0.38インチスペシャル 型回転弾倉式けん銃（以下，「38SPL 型けん銃」と 表記する.）の中には S\&W 等を模倣したパルティ ックと呼ばれる密造銃があり，押収される $38 \mathrm{SPL}$ 型けん銃の 2 割 $\sim 3$ 割を占めている(1-4). 以前のパ ルティックは加工が劣悪であったため, パルティッ クから発射される弾丸は，一見してそれと判断する ことも可能であった。ところが，近年，パルティッ クの中に加工程度の良いものが現れ, 正規銃から発 射されたものではないかと判断に迷うケースも出て きた。

一般的に，パルティックは，正規に製造されたけ 几銃（以下「正規銃」と称する.）に比べて銃腔径 が小さいものが多い。よって，弾径が正規銃のもの より明らかに小さければ，パルティックから発射さ れた弾丸と判断できる.

発砲事件で現場から発見される弾丸は, 構造物等 との衝突により変形をたは破片化している．特に， 38SPL 型けん銃で使用される実包には鉛弾が多 く, 変形を受けやすい。衝突による弾頭部の変形 は, 弾底部の直径にも影響を及ぼすため, 変形した 弾丸では変形前の弾径を見積もる必要がある. 推定 された銃腔径が正規銃より小さい場合は，腔旋痕が 良好であってもパルティックから発射された可能性 を考えなければならない。

前報では，正規の38SPL 型けん銃を用い，厚鋼 板，コンクリートブロックおよびポリカーボネート 板を被射体に，垂直方向から鉛弾，半被甲弾抢よび 全被甲弾を衝突させた実験について報告した。その 結果，厚鋼板に対する鉛弾の衝突では，弾底部にお いて最大 $0.60 \mathrm{~mm}(9.00 \mathrm{~mm} \rightarrow 8.40 \mathrm{~mm}, 6.7 \%)$ の 収縮が見られ，腔旋痕角においては，平均で $0.79^{\circ}$ $\left(3.30^{\circ} \rightarrow 2.51^{\circ}, 24 \%\right)$ の減少が見られた ${ }^{5}$.

銃腔径の小さいパルティックから発射される鉛弾 は，正規銃から発射される弾丸に比べると細長い形 状となる．そのためパルティックから発射された弾 丸が，正規銃の場合と同じような变形特性を示すの か確認しておく必要がある.

本報では, 銃腔径（旋丘径）が $8.45 \mathrm{~mm}$ のパル ティックを用い，厚鋼板への鉛弾の衝突実験を行 い，前報の正規銃による実験結果と比較検討を行っ たので，その結果を報告する.

\section{材料および方法}

\section{1 供試けん銃}

実験には口径0.38インチスペシャル型回転弾倉式 のパルティックを用いた. Fig. 1 に供試けん銃の外 観を示す．主な諸元は Table 1 のとおりである.

\section{2 供試実包}

実験に用いた実包は，前報で鉛弾（A）と呼んで いたもので，アメリカ合衆国レミントン銃器会社製 のラウンドノーズ型鉛弾である. Fig. 2 に, 前回の

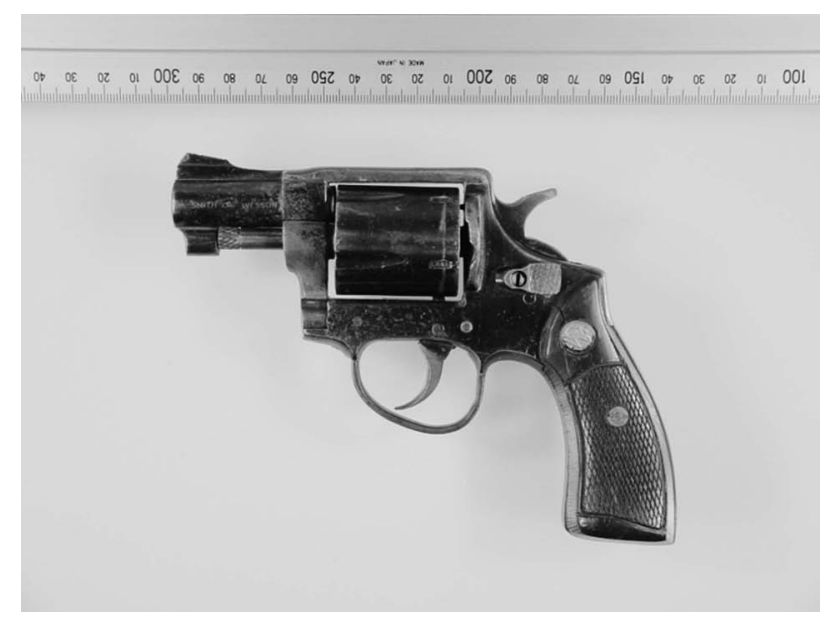

Fig. 1 Paltik used in the study. 
Table 1 Feature of test handgun.

\begin{tabular}{ll} 
Barrel length & $52.1 \mathrm{~mm}$ \\
Bore diameter & $8.45 \mathrm{~mm}$ \\
Direction of twist & Right \\
Number of grooves & 6 \\
Land width & $1.73 \sim 2.10 \mathrm{~mm}$ \\
Average angle of twist & $6.90^{\circ}$ \\
\hline
\end{tabular}

(a)

(b)
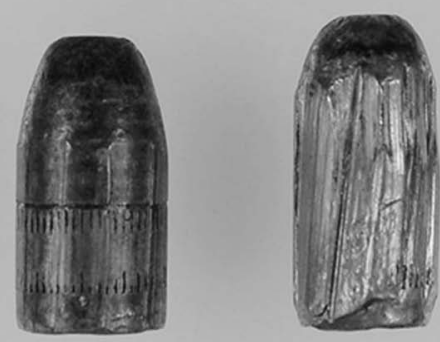

Fig. 2 Figure of bullets fired from Paltik and authentic gun.

(a) Authentic Gun, (b) Paltik

正規銃による試射弾丸と今回の供試パルティックに よる試射弾丸の外観を示す。供試パルティックによ る弾丸は，腔旋痕が粗雑であり，全体的に細長く変 形している.

\section{3 被射体}

弾丸を衝突させる被射体として，前報でも用いた 厚鋼板（300 mm × 400 mm，厚さ20 mm）を使用し た. 厚鋼板は固定しており, 変形も生じないため, 対固定壁衝突と考えてよい.

\section{4 試射方法}

固定した被射体に対して $2 \mathrm{~m}$ の射距離を設け， 被射体に対して垂直方向から試射を行った. 弾丸の 速度は実包の発射薬量を調節して变化させた。 た，けん銃と被射体の間に弾速計（侏小野測器製 LS-1000）を設置し，弾速を測定した.

\section{5 諸元の測定}

\section{（1）弾丸の変形率}

弾丸の変形程度を評価するために，変形率 $\mathrm{R}$ を
次のように定義した。なお，変形前の弾長について は無変形の発射弾丸の全長を, 変形後の弾長につい ては弾丸の中心軸上の長さをノギスで測定した.

$$
\begin{aligned}
\mathrm{R} & =\frac{\mathrm{L}-\mathrm{L}^{\prime}}{\mathrm{L}} \\
\mathrm{R} & : \text { 弾丸の変形率 } \\
\mathrm{L} & : \text { 変形前の弾長 } \\
\mathrm{L}^{\prime} & : \text { 変形後の弾長 }
\end{aligned}
$$

\section{（2）弾径}

弾丸の直径は, 弾底部に最も近い弾丸側面に相当 する部分において長径と短径をノギスで測定し，そ の平均值を用いた.

$$
\begin{aligned}
\mathrm{D}=\frac{\mathrm{D}_{\max }+\mathrm{D}_{\min }}{2} \\
\mathrm{D}: \text { 弾径の平均值 } \\
\mathrm{D}_{\max } \text { : 弾丸の長径 } \\
\mathrm{D}_{\min } \text { : 弾丸の短径 }
\end{aligned}
$$

\section{（3）腔旋痕角}

腔旋痕角の測定にはシャドウグラフ（珠)ミツトヨ 製 PJ-3000F）を用いた。変形した弾丸は，角度の 基準となる弾軸の特定が困難であるので, 弾丸を保 持具に固定し，保持具の回転軸を基準に各腔旋痕の 相対角度を測定して平均值を求めた ${ }^{6)}$. なお, 前報 では詳述しなかったが，同様の方法を用いて測定を 行っている.

$$
\theta=\frac{\theta_{1}+\theta_{2}+\theta_{3}+\theta_{4}+\theta_{5}+\theta_{6}}{6}
$$

$\theta:$ 腔旋痕角の平均值

$\theta_{1} \sim \theta_{6}:$ 各腔旋痕角の測定值

\section{結果および考察 \\ 1 弾丸の速度と変形率の関係}

Fig. 3 は弾速と弾丸の変形率の関係を示したもの である.グラフには同じ条件で試射したときの正規 銃のデータも併せて示した. 正規銃の最高速度が約 $220 \mathrm{~m} / \mathrm{sec}$ であったのに対し, 供試パルティックは 最高で約 $180 \mathrm{~m} / \mathrm{sec}$ であった.この弾速の差は, 銃 腔径が小さいことによる抵抗の増加や弾倉と銃身の 隙間寸法などに起因していると考えられる.

実験の結果, 正規銃の場合と同様に, 变形率は弾 速約 $150 \mathrm{~m} / \mathrm{sec}$ までは直線的に増加し, それ以上の 


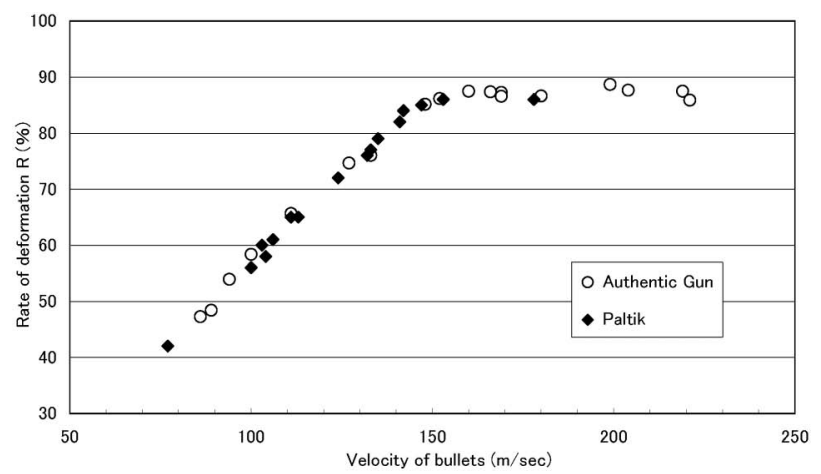

Fig. 3 Rate of deformation of bullets.

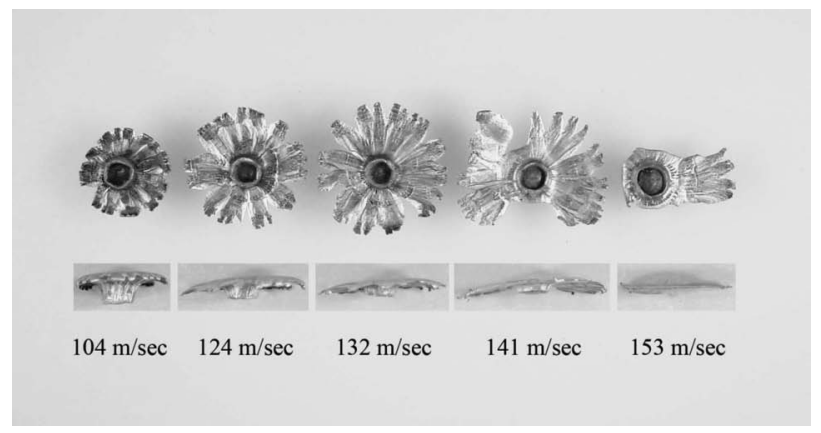

Fig. 4 Example of deformed bullets.

速度領域ではほぼ一定であった。変形率が速度に比 例して増加する領域では, 弾丸の運動エネルギは変 形によって吸収されている，また，変形率が一定と なる領域では, 弾丸の破片化が進行し, 四方へ飛散 している状態である。

Fig. 4 に速度変化に伴う変形例を示す. 破片化し た弾丸については弾底部分のみを示した。

\section{2 弾径の変化}

供試パルティックから発射される弾丸の直径を測 定したところ，平均で $8.58 \mathrm{~mm}$ であった。Fig. 5 は, 弾丸の変形率と弾径の収縮一拡大率の関係を示 したものである.グラフには正規銃によるデータも 併せて示した.

実験の結果，正規銃の場合と同じような变形特性 であった. 変形率76\%のとき弾径は最も収縮し, 変 形前の弾径に対して0.59 mm $(8.58 \mathrm{~mm} \rightarrow 7.99 \mathrm{~mm}$, 6.9\%）の減少であった，正規銃に打ける同条件の 実験では，変形率 $75 \%$ のとき $0.60 \mathrm{~mm}(9.00 \mathrm{~mm}$ $\rightarrow 8.40 \mathrm{~mm}, 6.7 \%$ ）の減少であった。変形率が約 80

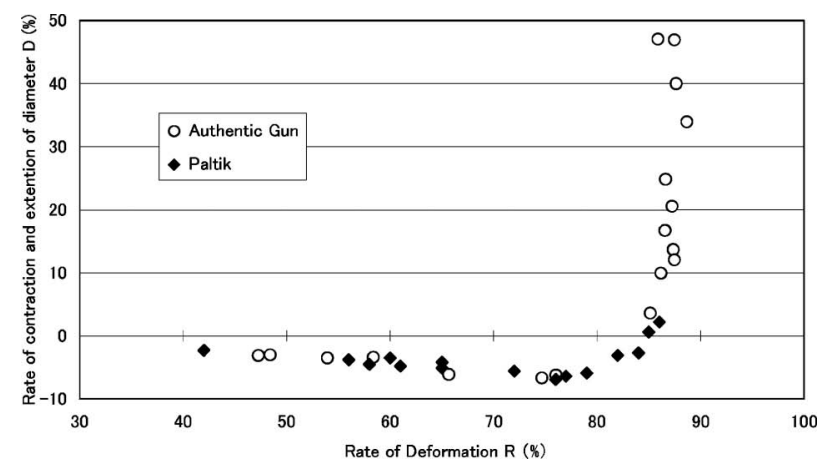

Fig. 5 Diameter changes found in base of deformed bullets.

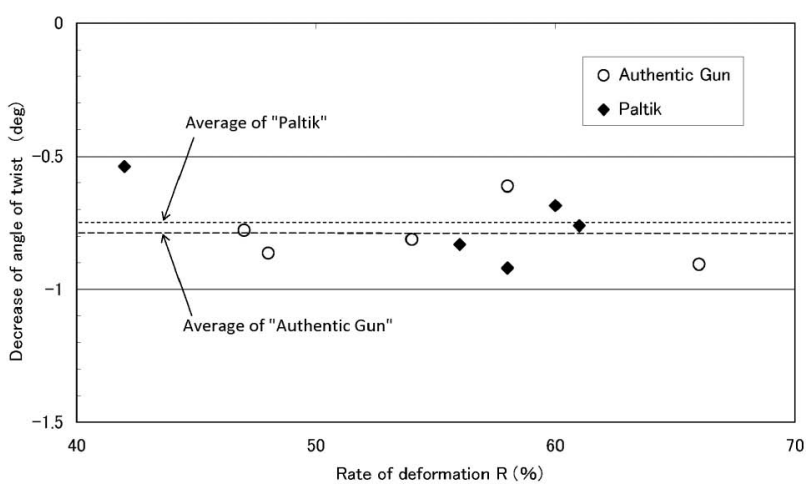

Fig. 6 Angle of twist measured on deformed bullets.

\%を超えると弾径は拡大に転じるが，供試パルティ ックは正規銃に比べて最高速度が低かったため，拡 大率は最大で $2 \%$ 程度に止まった。

なお，正規銃を用いてコンクリートブロックに鉛 弾を衝突させた実験では, 変形率57\%のとき， 0.67 $\mathrm{mm}(9.00 \mathrm{~mm} \rightarrow 8.33 \mathrm{~mm}, 7.4 \%)$ の収縮が見られ た.

\section{3 腔旋痕角の変化}

Fig. 6 は, 弾丸の变形率と腔旋痕角の減少の関係 を示したものである.グラフには正規銃のデータも 併せて示した．変形率が大きくなると腔旋痕角の測 定が困難になるため，グラフには測定が可能だった ものだけを示した。

実験の結果, 供試パルティックの腔旋痕角は, 平 均で $0.75^{\circ}\left(6.90^{\circ} \rightarrow 6.15^{\circ}, 11 \%\right)$ の減少が見られた. 正規銃に打ける同条件の実験では約 $0.79^{\circ}\left(3.30^{\circ} \rightarrow\right.$ $\left.2.51^{\circ}, 24 \%\right)$ の減少であった. 
腔旋痕角の減少を絶対值 $\left(^{\circ}\right)$ で表わした場合， 正規銃と供試パルティックの間に大きな差は見られ なかった．この腔旋痕角の減少を初期值に対する割 合（\%) で表わすと大きく異なってくる. 衝突によ る腔旋痕角の減少は, 弾丸の衝突速度, 弾丸の旋転 速度, 被衝突物の種類などが影響すると考えられ る．実験に用いた正規銃と供試パルティックは腔旋 痕角に大きな違いがあり，弾丸の旋転速度に差はあ ったと考えられる。しかし，今回の 2 丁のけん銃に よる実験では，腔旋痕角の減少（絶対值）に大きな 差は見られなかった。これについては，さらなる検 証が必要と考える.

\section{結 語}

38SPL 型のパルティック（銃腔径（旋丘径） 8.45 $\mathrm{mm}$, 発射弾丸の直径 $8.58 \mathrm{~mm}$ ) を用い, 厚鋼板に 対して鉛弾を垂直に衝突させ，弾丸の変形に伴う弾 径および腔旋痕角の変化を調べた。前報の正規銃 （発射弾丸の直径 $9.00 \mathrm{~mm}$ ) を用いた同じ条件下で の実験結果と比較すると以下のと抢りである.

（1）供試パルティックに括いては，最大 0.59 $\mathrm{mm}(8.58 \mathrm{~mm} \rightarrow 7.99 \mathrm{~mm}, 6.9 \%)$ の弾径の収縮が 見られた．正規銃のときは，最大 $0.60 \mathrm{~mm}(9.00$ $\mathrm{mm} \rightarrow 8.40 \mathrm{~mm}, 6.7 \%$ ）の収縮であった.

（2）腔旋痕角の変化については，供試パルティ
ックの場合, $0.75^{\circ}\left(6.90^{\circ} \rightarrow 6.15^{\circ}, 11 \%\right)$ の減少で あった．正規銃のときは, $0.79^{\circ}\left(3.30^{\circ} \rightarrow 2.51^{\circ}, 24\right.$ \%)の減少であった。

今回, 実験に用いたパルティックについて見る限 り, 発射された弾丸の変形特性に関して正規銃の場 合と顕著な差は見られなかった。38SPL 型けん銃 から発射される鉛弾に関しては, 変形によって弾底 部の直径に最大 $7 \%$ 程度の収縮が生じることが判明 した。

\section{文 献}

1）内山常雄 : 押収けん銃の傾向とその腔旋痕諸元 2005. 科警研報告， 57，36-43（2006）。

2）内山常雄 : 押収けん銃の傾向とその腔旋痕諸元 2004. 科警研報告， 56, 44-52（2006）。

3）内山常雄 : 押収けん銃の傾向とその腔旋痕諸元 2003. 科警研報告， 56, 36-43（2006）.

4）内山常雄：押収けん銃の傾向とその腔旋痕諸元 2002. 科警研報告， 55, 31-40（2003）。

5）水本光浩：弾丸の変形に伴う弾径と腔旋痕角の 変化. 日本法科学技術学会誌, $12-1,35-43$ (2007).

6）水本光浩 : 弾丸の腔旋痕角の測定方法に関する 一考察. 日本法科学技術学会誌第14回学術集会講 演要旨集, 13, 126 (2008). 